\title{
To Teach is to Learn
}

Sara Hussain, 1 Sahar Hussain.²

\section{The Letter}

I am writing this letter in response to your published article titled 'Sixth Class Students' Performance and Confidence Levels Before and After Training in Clinical Skills Laboratories'.

The initial years spent training as a prospective physician are known to be stressful, however, certain measures can be undertaken to make the transition to becoming a clinician less difficult. ${ }^{2-5}$ These include more exposure to patients and a working hospital environment, reducing external stressors, and using alternative methods of teaching which may include practical training in clinical skills laboratories, as well as peer assisted learning. 1, 6-10

We are living in an age of fast paced education, where textbooks are filled with hundreds of years of research that must be instilled into young minds in the most efficient and painless manner possible. While many concepts can be employed to help ease the course of education as mentioned above; studying among and teaching other students who are at the same level of learning is known to be one of the better known and encouraged methods of acquiring knowledge. ${ }^{11}$ A study conducted in 2014 compared the free recall between a group of students who were told they would be tested on a topic, and one who were told they would need to teach it to another student. The group that were expecting to teach answered more questions correctly and overall fared better over the second group. ${ }^{12}$

Peer learning, otherwise known as learner centered education, refers to the concept of students learning with and from each other throughout the course of their education. This is usually done withou an authoritative figure but may also be the part of a larger class discussion. If done in the correct manner, group studying can result in better learning than conventional methods; group discussions lead to active thinking about material, analysis and discussion of ideas, and therefore a more coherent processing of concepts.

Studying among peers also has the added benefits of developing confidence, critical thinking, communication, and problem-solving skills. Finally, and most importantly, this also develops an insight into self-learning skills, which could potentially become a lifelong asset to develop. 9-11 $^{-1}$

While teaching other students it would be wise to keep in mind that not everyone has the same amount of prior knowledge about the topic so finding a mutual common ground from where information can be built upon is vital. Keeping this in mind, prior research of the chapter beforehand helps to set a framework for the session to come. When planning the group session, a clear and concise plan needs to be arranged for the topics that are to be covered. Topics may be divided or allocated depending on individual preferences, or according to time allocated for study.

During the session itself, various adjuncts of study can be used to facilitate memory and recollection. Mnemonics, pictograms, and diagrams help; but mind maps help keep everyone on the same track throughout the discussion. Repeat often and link thoughts and ideas together while keeping in mind that group study should be a place where understanding the concept behind an idea is the main priority. Information that is understood does not need to be memorized - it can simply be linked to other ideas and built upon as needed. Additionally, summarizing the knowledge at the end of the session goes a long way towards consolidating the information for a longer period.

Student group studies can also go beyond the theoretical - practical sessions are especially helpful if overseen by a stand-in 'examiner'. This is especially beneficial if practiced on a mannequin, as the session can then be repeated as many times as necessary. ${ }^{1}$ Ideas can then be freely shared to improve and enhance the methods of clinical examination.

However, learning does not necessarily have to be a planned and dated arrangement. Spontaneous 'bites' of education are often the easiest to digest and remember. Keeping in mind that not everyone memorizes information the same way - so the goal of the session should be a sharing of knowledge and a place to clear up questions, rather than a final discussion with no revision.

As medicine is always easier to remember by case-based discussion, this can be a good starting point for the learning session and an easy way to link ideas together. Where patient centered learning may not be applicable, question solving can stimulate creative thinking and discussion between peers and may pave the way to finding a rhythm for the learning session.

A classroom where peer learning is advocated and encouraged leads to a more interactive and stimulating learning environment. But while learner centered education can enhance and embellish a teaching session, it should never completely take over a learning institution or method. Teachers always have, and always will be a fundamental part of society, both to oversee and guide young minds towards independent thinking; and to build them as individuals.

1 Degree, Dr., Rashid Hospital, Dubai Health Authority, Dubai, United Arab Emirates.

2 Dr., Dubai Pharmacy College. Dubai, United Arab Emirates.

About the Author: Dr. Hussain is affiliated with the Rashid Hospital, Dubai Health Authority, Dubai, United Arab Emirates.

Correspondence:

Dr. Sara Hussain 


\section{References}

1. Abualhayja'a AM, Ankarali H, Alyacoub R, Abudayeh A, Alsaoud S, Alsaeidi O. Sixth Class Students' Performance and Confidence Levels Before and After Training in Clinical Skills Laboratories. Int J Med Students. 2017;5(1), 26-31.

2. Nechita F, Nechita D, Pîrlog M, Rogoveanu I. Stress in medical students. Rom J Morphol Embryol. 2014;55(3 Suppl):1263-6.

3. Ludwig $A B$, Burton W, Weingarten J, Milan F, Myers DC, Kligler B. Depression and stress amongst undergraduate medical students. BMC Med Educ. 2015 Aug 27;15:141.

4. Qamar K, Khan N, Bashir Kiani M. Factors associated with stress among medical students. J Pak Med Assoc. 2015;65(7), 753-755.

5. McLuckie A, Matheson K, Landers A, Landine J, Novick J, Barrett T, Dimitropoulos C. The Relationship Between Psychological Distress and Perception of Emotional Support in Medical Students and Residents and Implications for Educational Institutions. Acad Psychiatry. 2017 Nov 9. doi: 10.1007/\$40596-017-0800-7.

6. Han ER, Chung EK, Nam KI. Peer-Assisted Learning in a Gross Anatomy Dissection Course. Mihlbachler MC, ed. PLOS ONE. 2015;10(11):e0142988. doi: 10.1371/journal.pone.0142988.
7. Alvarez S, Dethleffsen K, Esper T, Horneffer A, Reschke K, Schultz J. An overview of peer tutor training strategies at German medical schools. Z Evid Fortbild Qual Cesundhwes. 2017 Oct;126:77-83. doi: 10.1016/j.zefq.2017.09.009.

8. De Silva NL, Parththipan B, Rodrigo C, Constantine C, Fernando SD, Rajapakse S. Peer assisted learning among Sri Lankan medical undergraduates: a cross sectional study. BMC Research Notes. 2017;10:595. doi:10.1186/s13104-017-2920-2.

9. Zentz S, Kurtz C, Alverson E. Undergraduate peer-assisted learning in the clinical setting. J Nurs Educ. 2014;53(3):S4-S10. doi: 10.3928/01484834-20140211-01.

10. Pegram A, Fordham-Clarke C. Implementing peer learning to prepare students for OSCEs. Br J Nurs. 2015;24(21):1060-1065. doi:10.12968/bjon.2015.24.21.1060.

11. Boud D, Cohen R, Sampson J. Peer Learning in Higher Education. London: Kogan Page Limited; 2001.

12. Nestojko J, Bui D, Kornell N, Bjork E. Expecting to teach enhances learning and organization of knowledge in free recall of text passages. Memory a Cognition. 2014;42(7):1038-48.

\section{Acknowledgments}

None.

Conflict of Interest Statement at Funding

The Authors have no funding, financial relationships or conflicts of interest to disclose.

Author Contributions

Conception and design the work/idea, Collect data/obtaining results, Analysis and interpretation of data, Write the manuscript, Critical revision of the manuscript, Approval of the final version: $\mathrm{SH}, \mathrm{SH}$.

Cite as:

Hussain S, Hussain S. To Teach is to Learn. Int J Med Students. 2018 Jan-Apr;6(1):31-32. 